\title{
POR UM TRATAMENTO EFICIENTE DA PROVA: NOTAS SOBRE O MULTIDISTRICT LITIGATION ENQUANTO TÉCNICA COLETIVA DE GESTÃO DE PROCESSOS ${ }^{1}$
}

\section{FOR AN EFFICIENT TREATMENT OF EVIDENCE: THE MULTIDISTRICT LITIGATION AS A COLLECTIVE CASE MANAGEMENT TECHNIQUE}

Giulia Zanetti

Bacharela em Direito pela Universidade Positivo. PósGraduanda em Direito Processual Civil pela Universidade Dom Bosco. Curitiba, Paraná, Brasil. E-mail: giuliazaanetti@gmail.com

Thaís Amoroso Paschoal Doutora e Mestre em Direito das Relações Sociais pela Universidade Federal do Paraná. Professora de Direito Processual Civil na Universidade Positivo, em Curitiba/PR, e Supervisora do Núcleo de Prática Jurídica dessa Instituição. Professora em cursos de pós-graduação. É membro integrante do Instituto Brasileiro de Direito Processual. Integrante do Núcleo de Pesquisa Constitucionalismo e Democracia: filosofia e dogmática constitucional contemporâneas e do Núcleo de Pesquisa Direito Processual Civil Comparado, do PPGD-UFPR. Curitiba, Paraná, Brasil. E-mail: thaisamorosopaschoal@gmail.com

RESUMO: O presente artigo analisa o multidistrict litigation do direito norte americano como forma de proporcionar um tratamento adequado às causas que possuam questões de fato semelhantes e que, por isso, admitam instrução probatória conjunta. Partindo da consideração de que cada processo faz parte de um conjunto de processos que integram o

\footnotetext{
${ }^{1}$ Artigo recebido em 06/10/2020 e aprovado em 15/12/2020.
} 
amplo espectro de atuação do Poder Judiciário brasileiro, posiciona-se o MDL como inspiração para uma gestão da prova com foco na eficiência com qualidade, à luz da proporcionalidade pan processual. Para tanto, apresenta-se a ferramenta enquanto técnica de coletivização da prova, num contexto de gestão de casos judiciais.

PALAVRAS-CHAVE: Gestão de casos. Eficiência. Proporcionalidade pan processual. Prova. Multidistrict litigation.

ABSTRACT: This article analyzes the multidistrict litigation of North American law as a way of providing an adequate treatment to causes that have similar issues of fact and that, therefore, admit joint evidential instruction. Based on the consideration that each case is part of a set of cases that integrates the broad spectrum of action of the Brazilian Judiciary, the MDL is positioned as an inspiration for the management of evidence with a focus on efficiency with quality, under the pan procedural proportionality. For this purpose, the tool is presented as a technique for collecting evidence, in a context of management of judicial cases.

KEY WORDS: case management. Efficiency. Pan-procedural proportionality. Evidence. Multidistrict litigation.

\section{Introdução}

Ao pensar a ideia de Jurisdição no Estado Constitucional ${ }^{2}$, Remo Caponi afirma que essa não pode ser concebida apenas como uma função do Estado voltada à atuação do Direito no caso concreto, mas principalmente, como "serviço público orientado à

\footnotetext{
${ }^{2}$ Luiz Guilherme Marinoni, acerca da concepção de processo no Estado Constitucional, afirma que "o processo deixou de ser um instrumento voltado à atuação da lei para passar a ser um instrumento preocupado com a proteção dos direitos, na medida em que o juiz, no Estado Constitucional, além de atribuir significado ao caso concreto, compreende a lei na dimensão dos direitos fundamentais" (MARINONI, Luiz Guilherme. Teoria geral do processo. São Paulo: Revista dos Tribunais, 2006, p 405).
} 
composição das controvérsias segundo a Justiça", o que possibilita que a Justiça seja voltada a "responder às expectativas de eficiência provenientes dos usuários do serviço judiciário". 3

Já em sua exposição de motivos, o Código de Processo Civil de 2015 apresenta a necessidade de um sistema eficiente, proporcionando a efetivação e a realização dos direitos, afirmando que a pretensão do Código é a consecução de um processo mais célere e justo. ${ }^{4}$ De fato, não se pode mais pensar a atividade jurisdicional de forma isolada, sem a consideração do conjunto de processos que a cada dia tornam essa atividade um complexo de atos voltados à gestão da Justiça. Com um Judiciário que possui uma das maiores taxas de congestionamento do mundo ${ }^{5}$, é inequívoca a necessidade de se buscar no Brasil ferramentas que possibilitem a gestão adequada de casos judiciais.

Para se atingir o objetivo proposto pela atividade judicatória, prestando o serviço jurisdicional de forma eficaz, Remo Caponi enuncia que processo eficiente é aquele em que se conjugam três fatores: o legislativo, o de recursos e o cultural. No que concerne ao fator recursos, trabalha a necessidade de verificar a disponibilidade de recursos humanos e materiais efetivamente disponíveis para que o Poder Judiciário trate adequadamente todas as causas a ele apresentadas. Deve o magistrado, portanto, ao tratar uma causa, estabelecer um equilíbrio entre os recursos empregados na proteção dos interesses individuais que compõem a causa singular e, ainda, os interesses coletivos em seu complexo, correspondentes aos usuários potenciais ou atuais do serviço jurisdicional. ${ }^{6}$

\footnotetext{
${ }^{3}$ CAPONI, Remo. O princípio da proporcionalidade na Justiça Civil. In Revista de Processo n. 192. São Paulo: Revista dos Tribunais, 2011, p. 401.

${ }^{4}$ BRASIL. Código de Processo Civil e normas correlatas, 7. ed. Exposição de motivos. Brasília: Senado Federal, Coordenação de Edições Técnicas, 2015. Disponível em https://www2.senado.leg.br/bdsf/bitstream/handle/id/512422/001041135.pdf, acesso em 15 set 2020.

5 A taxa de congestionamento é calculada a partir da consideração de casos novos, casos pendentes e casos resolvidos pelo Judiciário. Relatório elaborado pelo Departamento de Pesquisas Judiciárias do Conselho Nacional de Justiça em novembro de 2011 indicava que, no Brasil, a taxa de congestionamento era de 70\%, contra uma média de $47 \%$, calculada com base em 30 países europeus (BRASIL. Conselho Nacional de Justiça. Estudo comparado sobre recursos, litigiosidade e produtividade: a prestação jurisdicional no contexto internacional. Disponível em https://www.cnj.jus.br/wpcontent/uploads/2011/02/relat_estudo_comp_inter.pdf Acesso em 11. Set. 2020). O Relatório Justiça em Números produzido pelo Conselho Nacional de Justiça em 2019, com referência ao ano de 2018, indica que o "no primeiro grau de jurisdição está o maior volume processual, com 93,9\% dos casos pendentes, 84,1\% dos casos dos casos novos, $84 \%$ dos servidores da área judiciária e 86,1\% dos magistrados" (BRASIL. Conselho Nacional de Justiça. Justiça em números 2019: ano-base 2018. Brasília: CNJ, 2019, p. 220). Os dados deixam claro o impacto que o $1^{\circ}$ grau gera tanto no que se refere aos casos novos quanto aos casos pendentes. A taxa líquida de congestionamento nessa instância, em 2018, foi de 68,9\%, contra 46,4\% em $2^{\circ}$ grau (Ibidem, p. 120). ${ }^{6}$ CAPONI, Remo. O princípio da proporcionalidade na Justiça Civil. In Revista de Processo n. 192. São Paulo: Revista dos Tribunais, 2011, p. 400 e 402. Ainda, ver OSNA, Gustavo. Direitos Individuais Homogêneos:
} 
É nesse contexto que se pretende analisar instituto que se insere no contexto do case management do direito norte americano. Trata-se do multidistrict litigation, ferramenta por meio da qual se possibilita a reunião de processos em trâmite perante juízos federais distintos, possibilitando a produção de provas em um único juízo e, por essa razão, será aqui tratada como importante ferramenta coletiva de gestão de casos.

\section{Limites materiais da Jurisdição}

No que concerne ao adequado tratamento a ser dado aos processos judiciais, sob a perspectiva panprocessual ${ }^{7}$, não é novidade a relevância de se discutir e trazer à tona as questões relativas à tutela coletiva ${ }^{8}$ no Brasil, país que conta, predominantemente, com uma cultura do litígio individual ${ }^{9}$ e, consequentemente, com o sistema judiciário excessivamente obstruído. ${ }^{10}$

Pressupostos, fundamentos e aplicação no processo civil. $1^{\text {a }}$ ed. São Paulo: Revista dos Tribunais, 2014, p. 41 et seq.

${ }^{7}$ Gustavo Osna explora o fato de que os recursos, tanto financeiros como humanos, são escassos, o que Gustavo Osna explora o fato de que os recursos, tanto financeiros como humanos, são escassos, o que acarreta a incapacidade material do sistema para oferecer a mesma dedicação a todas as demandas ajuizadas, afirmando, na esteira do que disse Remo Caponi, que essas devem ser tratadas com proporcionalidade, não apenas no âmbito endoprocessual, mas sob um olhar macroscópico (OSNA, op. cit., p. 91), incorrendo no que Sérgio Cruz Arenhart denomina proporcionalidade panprocessual. (ARENHART, Sérgio Cruz. A Tutela Coletiva de Interesses Individuais: para além da proteção dos interesses individuais homogêneos. $1^{a}$ ed. em e-book baseada na $2^{\mathrm{a}}$ ed. impressa. São Paulo: Revista dos Tribunais, 2015, não paginado. Ver, ainda, OSNA, op. cit, p. 46. E, também, ARENHART, Sérgio Cruz. OSNA, Gustavo. Curso de Processo Civil Coletivo. $2^{\mathrm{a}}$ ed. São Paulo: Revista dos Tribunais, 2020, passim).

${ }^{8}$ ARENHART, op. cit., não paginado.

${ }^{9}$ Acerca do tema, Gustavo Osna afirma que a facilitação de acesso ao Poder Judiciário por meio de políticas como a instituição dos juizados especiais e a consolidação da benesse da justiça gratuita, decorrente da legítima preocupação de garantir o acesso à Justiça, previsto no texto constitucional, tende a gerar um aumento de procura. No entanto, há de ressaltar que acesso ao Poder Judiciário e acesso à Justiça são conceitos distintos entre si. (OSNA, Gustavo. Direitos Individuais Homogêneos: Pressupostos, fundamentos e aplicação no processo civil. $1^{\text {a }}$ ed. São Paulo: Revista dos Tribunais, 2014, passim). No mesmo sentido, Ada Pellegrini Grinover afirma que garantir que às partes meios para que levem suas pretensões ao Poder Judiciário não é o mesmo que lhes garantir acesso à justiça. (GRINOVER, Ada Pellegrini. Deformalização do processo e deformalização das controvérsias. In Revista de Processo n. 46. São Paulo: Revista dos Tribunais, 1987, p. 69).

${ }^{10}$ Anualmente, o Conselho Nacional de Justiça elabora o Relatório Justiça em Números, que tem o condão de possibilitar uma análise completa do desempenho do Poder Judiciário, apresentando um diagnóstico amplo que compreende aspectos relacionados à estrutura do Poder Judiciário, aos recursos humanos e financeiros por ele utilizados e, também, a movimentação processual. No entanto, o relatório se limita ao prisma qualitativo. Não trabalha aspectos como a satisfação dos usuários do sistema com a forma como a prestação da tutela jurisdicional vem sendo prestada. Por mais que trabalhe os índices de recorribilidade, de acordo com Alexandre Samy Castro "A avaliação da qualidade da prestação jurisdicional com base em indicadores quantitativos é alvo de críticas por ignorar a dimensão qualitativa das decisões judiciais. Isto é, a quantidade de sentenças proferidas por um juiz per se não permite que se mensure o valor social da prestação jurisdicional, visto que 
A fim de ilustrar a natureza dos processos que inundam o Poder Judiciário brasileiro, o CNJ, por meio da pesquisa intitulada 100 Maiores Litigantes, elaborada no ano de 2011, verificou, no âmbito dos tribunais estaduais, federais e do trabalho, quais foram os cem maiores litigantes presentes nas ações judiciais. No panorama geral, verificou-se que as seis primeiras posições do ranking foram ocupadas por entes estatais que, juntos, litigavam em 53,73\% dos processos judiciais considerados. Em segundo lugar, ocupando as quatro posições seguintes, estavam instituições financeiras diversas. Considerando apenas a Justiça Estadual, verificou-se que os bancos ocuparam posições ainda mais elevadas, alcançando o segundo, terceiro e quinto lugares na colocação de maiores litigantes, atrás apenas do Estado do Rio Grande do Sul e do INSS, que ocupavam a primeira e a quarta posições. ${ }^{11}$

Quando considerados os setores de atividades, verificou-se que, em âmbito nacional, o setor público federal e os bancos litigaram em $76 \%$ do total de processos, dos quais em 38,5\% figurava o Estado e, nos 38,14\% restantes, os bancos, enquanto que, no âmbito da Justiça Estadual, as instituições financeiras estiveram em $54 \%$ do total. ${ }^{12} \mathrm{O}$ relatório evidenciou, ainda, que, do total de processos envolvendo os cem maiores litigantes do país, em $59 \%$ o litigante costumaz se encontra no polo passivo da ação. ${ }^{13}$

No mesmo sentido, pesquisa realizada pela Associação dos Magistrados Brasileiros, no ínterim compreendido entre 2010 e 2013, a que se atribuiu o título de $O$ Uso da Justiça e o Litígio no Brasil, revelou que há, no Judiciário nacional, uma elevada concentração de ações manejadas por ou em face de um número reduzido de atores, dentre

\footnotetext{
ignora dimensões como a complexidade dos casos e a correção (fairness) e previsibilidade das decisões judiciais". (CASTRO, Alexandre Samy. Indicadores Básicos e Desempenho da Justiça Estadual de Primeiro Grau no Brasil. Disponível em http://www.ipea.gov.br/portal/index.php?option=com_content\&view=article\&id=9605. Acesso em 12 ago. 2020). De qualquer modo, o relatório se utiliza de um indicador denominado Taxa de Congestionamento, que mede o percentual de casos que permaneceram pendentes de solução ao final do ano-base, comparativamente ao total tramitado no ínterim de um ano. Por meio do Relatório Justiça em Números 2020 evidenciou-se que a taxa de congestionamento, historicamente, se manteve em patamares superiores a $70 \%$ até que, no ano de 2019 , atingiu sua melhor marca, chegando ao índice de $68,5 \%$. No entanto, nos últimos dez anos, a sua maior oscilação havia sido verificada entre os anos de 2009 e 2010, com aumento de 1,4 ponto percentual. Ainda, expôs-se que a taxa de congestionamento média da Justiça Estadual no Brasil corresponde a $71 \%$ variando entre 49,1 no Tribunal de Justiça do Estado de Roraima e 75,4\% no Tribunal de Justiça do Piauí. (BRASIL. Conselho Nacional de Justiça. Justiça em números 2020: ano-base 2019. Brasília: CNJ, 2020)

${ }^{11}$ BRASIL. Conselho Nacional de Justiça. 100 Maiores Litigantes. Brasília, 2011, p. 5. Disponível em https://www.cnj.jus.br/wp-content/uploads/2011/02/pesquisa_100_maiores_litigantes.pdf. Acesso em 08 set. 2020.

${ }^{12}$ BRASIL, loc. cit.

${ }^{13}$ BRASIL, loc. cit.
} 
os quais se encontram a Fazenda Pública e suas instituições, bancos, prestadoras de crédito e, ainda, de serviços de telefonia e comunicações, o que, segundo o próprio relatório emitido pela AMB, é causa de extensos prejuízos à qualidade dos serviços judiciários. ${ }^{14}$

Em que pese as pesquisas mencionadas tenham sido realizadas há aproximadamente 10 anos, o Relatório Justiça em Números 2020, elaborado também pelo CNJ, evidencia que os assuntos mais demandados na Justiça Estadual, no ano de 2019, correspondem às ações envolvendo relação de consumo e obrigações contratuais, o que se repete nos juizados especiais e nas turmas recursais. ${ }^{15}$

Isso se evidenciou porque, com o advento da Revolução Industrial, propulsora da denominada Era da Informação e o consequente desenvolvimento das sociedades de massa ${ }^{16}$, assim como de um contexto social globalizado, surgiu a necessidade de se tutelar os interesses coletivos provenientes das mudanças sociais, uma vez que, conforme afirma Ada Pellegrini Grinover, interesses de massa comportam ofensas de massa. ${ }^{17}$

Assim, tendo o indivíduo buscado grupos como meio de assegurar a sua realização pessoal e, também, como forma de proteção ${ }^{18}$, não é, no contexto atual, adequado negar-lhe uma tutela jurisdicional que se adeque aos seus anseios e adaptações, de modo que se exige uma atuação mais efetiva e eficiente neste âmbito.

O que se quer dizer é que não se encontra a proporcionalidade quando dentro do mesmo sistema houver demasiado esforço estatal diante de determinados casos concretos pensando o processo à luz de casos isolados - em detrimento de outras demandas que também necessitem da adequada atenção do Poder Judiciário. Em outras palavras, e num

\footnotetext{
${ }^{14} \mathrm{O}$ relatório ainda expõe resultado de estudo realizado pelo Conselho Nacional de Justiça por meio do qual se constatou que o Brasil ocupa a $3^{\text {a }}$ posição em um ranking de produtividade no qual foram considerados 42 países, o que demonstra que, em que pese a força de trabalho empregada a fim de dar vasão às numerosas ações propostas no Poder Judiciário seja expressiva é, ainda, insuficiente. O Uso da Justiça e o Litígio no Brasil. Associação dos Magistrados Brasileiros, 2015. Disponível em https://www.amb.com.br/wpcontent/uploads/2018/05/Pesquisa-AMB-10.pdf - acesso em 09. Set. 2020.

${ }^{15}$ BRASIL. Conselho Nacional de Justiça. Justiça em números 2020: ano-base 2019. Brasília: CNJ, 2020.

${ }^{16}$ MILARÉ, Edis; CASTANHO, Renata. A distribuição do ônus da prova no Anteprojeto de Código Brasileiro de Processos Coletivos. In GRINOVER, Ada Pellegrini; MENDES, Aluisio Gonçalves de Castro; WATANABE, Kazuo (coord.) Direito Processual Coletivo e o Anteprojeto de Código Brasileiro de Processos Coletivos. São Paulo, Revista dos Tribunais, 2007.

${ }^{17}$ GRINOVER, Ada Pellegrini; WATANABE, Kazuo; MULLENIX, Linda. Os processos coletivos nos países de civil law e common law: uma análise de direito comparado. $1^{\text {a }}$ ed. São Paulo, Revista dos Tribunais, 2008, p. 231.

${ }^{18}$ MANCUSO, Rodolfo de Camargo. Interesses Difusos: conceito e legitimação para agir. $6^{\text {a }}$ ed. São Paulo, Revista dos Tribunais, 2004, p. 40.
} 
contexto de gestão externa de processos, é fundamental que, além das características específicas de cada causa, também se leve em consideração a relação de cada causa com o conjunto de processos que compõem o estoque do Judiciário.

Surge, então, um questionamento primordial ao desenvolvimento do presente estudo: há capacidade material para que seja ofertado um tratamento adequado às demandas ajuizadas perante o Poder Judiciário? Diante dos dados observados no Relatório Justiça em Números, elaborado pelo Conselho Nacional de Justiça, podemos concluir que o Poder Judiciário não conta com estrutura capaz de solucionar de forma satisfatória e em tempo razoável as demandas propostas. ${ }^{19}$

Anualmente, o Relatório Justiça em Números é elaborado pelo CNJ a fim de possibilitar uma análise completa do desempenho do Poder Judiciário, apresentando um diagnóstico amplo que compreende aspectos relacionados à estrutura do Poder Judiciário, aos recursos humanos e financeiros por ele utilizados e, também, à movimentação processual. $^{20}$

Diante da evidente insuficiência do Poder Judiciário para o trato com as demandas que atualmente se encontram em trâmite, é necessário pensar no adequado tratamento que deve ser dado às causas, observando-se o sistema como um todo e, manifestamente, não se dispendendo a mesma força de trabalho para causas simples (que não demandam tanto tempo e atividade) e causas complexas.

\footnotetext{
${ }^{19}$ Reconheceu-se, no Relatório Justiça em Números 2020, uma taxa de congestionamento de 68,5\% no ano base de 2019. Em que pese a mais baixa historicamente registrada, trata-se, ainda, de índice em patamar excessivamente elevado (BRASIL. Justiça em Números 2020: ano-base 2019. Brasília: Conselho Nacional de Justiça, 2020, p. 112)

${ }^{20}$ O Relatório Justiça em Números não trabalha aspectos como a satisfação dos usuários do sistema com a forma como a prestação da tutela jurisdicional vem sendo prestada. Por mais que trabalhe os índices de recorribilidade, de acordo com Alexandre Samy Castro "A avaliação da qualidade da prestação jurisdicional com base em indicadores quantitativos é alvo de críticas por ignorar a dimensão qualitativa das decisões judiciais. Isto é, a quantidade de sentenças proferidas por um juiz per se não permite que se mensure o valor social da prestação jurisdicional, visto que ignora dimensões como a complexidade dos casos e a correção (fairness) e previsibilidade das decisões judiciais". Mas, o autor afirma que tal crítica pode ser atenuada por meio das técnicas adequadas de pesquisa, concluindo que "há motivos para se crer que, em média, a eficiência produtiva de um tribunal é positivamente correlacionada com a qualidade da prestação jurisdicional deste tribunal, em termos de suas dimensões não observáveis, porém relevantes para uma avaliação abrangente do desempenho ou valor social da prestação jurisdicional.”. (CASTRO, Alexandre Samy. Indicadores Básicos e Desempenho da Justiça Estadual de Primeiro Grau no Brasil. Disponível em http://www.ipea.gov.br/portal/index.php?option=com_content\&view=article\&id=9605. Acesso em 20 mai 2020.
} 
Nesta ideia de otimizar o funcionamento do Poder Judiciário a fim de melhor atender os interesses do jurisdicionado, prestando-se a tutela e efetivando-se o direito material em tempo razoável, é fundamental que se compreenda o Poder Judiciário como importante espaço de gestão.

\section{Tutela adequada de direitos de massa}

Como já se viu, grande parte das ações que são submetidas ao Poder Judiciário versam sobre interesses decorrentes de direitos individuais homogêneos. Portanto, e como afirmam Gustavo Osna e Sérgio Arenhart, são passíveis de serem tutelados de forma coletiva, eis que devem ser entendidos como técnica processual para tratamento coletivo de direitos individuais. ${ }^{21}$ Tornou-se evidente o fato de que, havendo interesses individuais similares, deve-se viabilizar a sua proteção em conjunto, a fim de se prestigiar a isonomia no tratamento das questões e, ainda, a gestão otimizada dos recursos judiciais disponíveis. ${ }^{22}$ 23

Acerca dos benefícios provenientes da abordagem coletiva das questões, Michele Taruffo, ao expor os propósitos e objetivos do processo coletivo, elenca o fato de que aquele, em muitas ocasiões, é capaz de alcançar a alteração, no mundo fático, de condutas juridicamente relevantes, mesmo que esse não seja o intento primário da classe litigante. ${ }^{24}$

\footnotetext{
${ }^{21}$ ARENHART, Sérgio Cruz. OSNA, Gustavo. Curso de Processo Civil Coletivo. $2^{\mathrm{a}}$ ed. São Paulo: Revista dos Tribunais, 2020, p. 86. E, ainda OSNA, Gustavo. Direitos Individuais Homogêneos: Pressupostos, fundamentos e aplicação no processo civil. $1^{a}$ ed. São Paulo: Revista dos Tribunais, 2014, p. 82.

${ }^{22}$ Remo Caponi afirma que "a adequada disponibilidade de recursos tem pouca serventia se não é acompanhada da capacidade e da competência profissional em organizar de forma eficiente o seu emprego" (CAPONI, Remo. O princípio da proporcionalidade na Justiça Civil. In Revista de Processo n. 192. São Paulo: Revista dos Tribunais, 2011, p. 403).

${ }^{23}$ Acerca das vantagens do tratamento coletivo das questões comuns, por meio do processo coletivo, Edilson Vitorelli afirma que, em que pese o ordenamento jurídico nacional não impeça a discussão de questões comuns de modo simultâneo em ações individuais e coletivas, levando-se em conta a predileção dos atores pelo litígio individual, essa forma de prestação prejudica não apenas a isonomia e a economia de recursos como impede a solução do problema como um todo. (VITORELLI, Edilson. Processo Civil Estrutural. Salvador: JusPodivm, 2020, p.52). Na mesma esteira, Fredie Didier Jr. e Hérmes Zanetti afirmam que o processo coletivo é meio apto a promover a tutela do interesse público primário por meio do qual se pretende a solução de conflitos metaindividuais (JUNIOR, Fredie Didier; ZANETTI, Hérmes. Curso de Direito Processual Civil: Processo Coletivo. V.4, $14^{\mathrm{a}}$ ed. Salvador: JusPodivm: 2020, pp. 67/68).

${ }^{24}$ TARUFFO, Michele. Some Remarks on Group Litigantion in Comparative Perspective. In Duke Journal of Comparative \& International Law, n. 11. Durham: Duke Universtity, 2001, p. 407/408. Disponível em https://scholarship.law.duke.edu/djcil/vol11/iss2/12 acesso em 13 set. 2020.
} 
Nesse contexto, há de se falar na gestão de casos judiciais, que deve ser compreendida à luz do princípio da eficiência, previsto no artigo 37 da Constituição da República, como forma de viabilizar uma prestação jurisdicional adequada.

Gerir casos judiciais significa conduzir o processo com o olhar voltado aos inúmeros casos pendentes de julgamento, buscando soluções que possibilitem a prestação da tutela jurisdicional adequada, atendendo à garantia da inafastabilidade do controle jurisdicional e, ao mesmo tempo, permitam, num contexto global, a maior eficiência do Poder Judiciário. ${ }^{25}{ }^{26}$. Trata-se de forma de se implementar a proporcionalidade panprocessual.

Embora a prestação da tutela jurisdicional seja um dever do Estado e decorra da garantia da inafastabilidade do controle jurisdicional, é certo que esse dever poderá (e deverá) ser cumprido por meio de medidas que mobilizem menores custos humanos e financeiros, com a adequada alocação de recursos e esforços do Poder Judiciário. Todos esses fatores devem ser conjugados para que se obtenha do serviço jurisdicional a sua melhor prestação, considerando todo o conjunto de casos judiciais.

Com efeito, Remo Caponi afirma que "a adequada disponibilidade de recursos tem pouca serventia se não é acompanhada da capacidade e da competência profissional em organizar de forma eficiente o seu emprego". ${ }^{27}$ E acrescente-se: a efetividade da atividade jurisdicional, a partir de uma política de gestão de casos judiciais, depende da utilização da técnica adequada para tanto, que pode, no caso do Brasil, ser extraível do próprio texto legal já aprovado. Aí reside o fator legislativo que Remo Caponi inclui ao lado do fator dos recursos e do fator cultural, como fundamentais para tornar o processo eficiente. José Roberto dos Santos Bedaque afirma que essa eficiência será encontrada quando se possibilitar o alcance do escopo da atividade jurisdicional "com o máximo de eficácia e com o menor dispêndio de energia possível". ${ }^{28}$

\footnotetext{
${ }^{25}$ Válido ressaltar que as premissas de celeridade e efetividade não devem ser confundidas. O trâmite rápido de um processo judicial não necessariamente corresponde ao adequado, trazendo ao destinatário a prestação justa e efetiva por ele buscada.

${ }^{26}$ LUNARDI, Thaís Amoroso Paschoal. Coletivização da Prova. Técnicas de produção coletiva da prova e seus reflexos na esfera individual (tese de doutorado). Curitiba: Universidade Federal do Paraná, 2018, p. 33.

${ }^{27}$ CAPONI, Remo. O princípio da proporcionalidade na Justiça Civil. In Revista de Processo n. 192. São Paulo: Revista dos Tribunais, 2011, p. 403.

${ }^{28}$ BEDAQUE, José Roberto dos Santos. Efetividade do processo e técnica processual. São Paulo: Malheiros, 2006, p. 50.
} 
Dessa forma, buscando acompanhar a evolução e as modificações da sociedade, os artigos 67 a 69 do Código de Processo Civil, que compõem o Capítulo II da Lei, voltado à Cooperação Nacional, ou seja, a colaboração entre juízos diversos (inclusive de competências diversas dentro do Poder Judiciário), foram elaborados a fim de que sejam praticados os atos processuais necessários de maneira adequada, em processos variados. ${ }^{29}$ Com base nesses dispositivos, é possível defender formas típicas e atípicas de interação entre juízos de competências diversas, objetivando a prática compartilhada e eficiente de atos processuais $^{30}$.

No entanto, não se pode ignorar o fato de que o Direito Processual Civil brasileiro é estruturado sobre uma base voltada à tutela dos direitos individuais. Assim, quando interpretados e aplicados os seus dispositivos em ações que, essencialmente, trabalhem problemas coletivos, possivelmente não se alcançará o resultado pretendido. Faz-se necessário, portanto, como afirma Sérgio Cruz Arenhart, pensar na tutela desses direitos de modo a redimensionar os institutos do processo civil clássico. ${ }^{31}$

A título de exemplo, seria válido pensar na estruturação de varas especializadas no processamento e julgamento das questões coletivas, mesmo que o âmbito de sua competência extrapole os limites dos foros territoriais da Justiça comum, a fim de melhor atender os interesses do jurisdicionado, prestando-se a tutela e efetivando-se o direito material em tempo razoável, sendo essencial que o juiz se posicione como gestor do processo, ao lado das partes litigantes. ${ }^{32}$

\footnotetext{
${ }^{29}$ Vale ressaltar que a tentativa de implementação de um sistema de cooperação dentre juízos não teve no Código de Processo Civil de 2015. Em 2011, o Conselho Nacional de Justiça editou a Recomendação 38/2011, que teve por objeto tratar de mecanismos de cooperação, visando dar fluidez e agilidade ao sistema, facilitando a comunicação entre seus operadores dentro dos diferentes órgãos do Poder Judiciário (que, por mais que seja dividido em competências distintas, não deixa de ser um poder uno). Parte-se da ideia de que muito atos praticados entre juízos, inclusive de competências diversas, seriam desburocratizados, viabilizando uma melhor comunicação e interação entre ambos, visando atingir a melhor forma de concertação dos atos.

${ }^{30}$ Nesse sentido: LUNARDI, Thaís Amoroso Paschoal. Coletivização da Prova. Técnicas de produção coletiva da prova e seus reflexos na esfera individual (tese de doutorado). Curitiba: Universidade Federal do Paraná, 2018, passim.

${ }^{31}$ ARENHART, Sérgio Cruz. Perfis da tutela inibitória coletiva. São Paulo: Revista dos Tribunais, 2003, p.41.

${ }^{32}$ Isso porque a Constituição da República elenca, como um de seus mandamentos primordiais, a dignidade da pessoa humana, tendo como objetivo a edificação de uma sociedade livre, justa e solidária, o que requer a cooperação dos cidadãos, disposição da qual provém o modelo cooperativo de processo. Desse modo, as disposições legais devem ser vistas como um todo e interpretadas pelo viés das disposições constitucionais e dos princípios previstos no próprio Código de Processo Civil, como o Princípio da Cooperação, que foi expressamente positivado no artigo $6^{\circ}$ da lei. Nesse modelo, incumbe ao juiz o desempenho de duas funções: agir de forma isonômica em relação ao andamento do processo e; de forma desigual ao determinar que suas decisões sejam cumpridas. Como gestor, cabe ao magistrado da causa dialogar com os demais sujeitos
} 
De toda forma, considerando-se o aspecto democrático sob o qual foi desenvolvido o Código de Processo Civil de 2015, esse objetivou atingir a razoável duração do processo, estimular a solução consensual dos conflitos, o efetivo contraditório e a cooperação entre as partes da demanda e o Poder Judiciário. A lei visa, também, a diminuição da burocracia que permeou o processo civil até então, além de valorizar o autorregramento da vontade, o procedimento e o aproveitamento dos atos processuais e a uniformização das decisões judiciais, sendo um reflexo da evolução cultural no Brasil, além de possibilitar a continuidade de sua evolução.

Os arts. 67 a 69 do CPC possibilitam a adoção de ferramentas de gestão processual pelo magistrado junto às partes e também de forma colaborativa com outros juízos, otimizando o procedimento e a dispendiosa atuação da máquina judiciária.

Nesse sentido, tratando-se a ideia de cooperação como essencial no tratamento do Poder Judiciário, o dever de cooperação positivado no Código de Processo Civil abrange dois aspectos: interno, quando versa sobre a gestão interna dos atos do procedimento, e externo quando permite a conjugação de esforços entre juízos ${ }^{33}$, o que segue a premissa exposta por Remo Caponi, de que o tratamento de cada uma das controvérsias, mesmo que finde em sua adequada composição, não pode tomar o espaço da eficiência na gestão da massa de processos existente. ${ }^{34}$

Ao mesmo tempo, acerca da prova no processo, Michele Taruffo expõe a máxima de que se trata de elemento essencial à prolação de uma decisão adequada e justa, quando se intentar, por meio da ação judicial, alcançar o grau máximo de Justiça. Ainda, o autor atribui à prova produzida e consequentemente aos fatos verificados a característica de condição necessária à resolução acertada do conflito. ${ }^{35}$

processuais acerca dos rumos a serem seguidos pelo processo, cabendo a ele os deveres de esclarecimento, diálogo, prevenção e auxílio. Acerca do tema, ver MITIDIERO, Daniel. Bases para a construção de um Processo Civil Cooperativo: o direito processual civil no marco teórico do formalismo-valorativo (tese de doutorado). Porto Alegre: Universidade Federal do Rio Grande do Sul, 2007, passim.

${ }^{33}$ LUNARDI, Thais Amoroso Paschoal. Atos concertados entre juízes cooperantes como ferramenta adequada de gestão processual: uma possibilidade para a aplicação do multidistrict litigation no sistema brasileiro. In ARENHART, Sérgio Cruz; MITIDIERO, Daniel (coord.). Processo Civil entre a Técnica Processual e a Tutela Dos Direitos: Estudos Em Homenagem A Luiz Guilherme Marinoni. São Paulo: Revista dos Tribunais, 2017, p. 372.

${ }^{34}$ CAPONI, Remo. O princípio da proporcionalidade na Justiça Civil. In Revista de Processo n. 192. São Paulo: Revista dos Tribunais, 2011, p. 400.

${ }^{35}$ TARUFFO, Michele. La prueba. $1^{\text {a }}$ ed. Madrid: Marcial Pons, 2008, passim. 
A importância da instrução probatória nos litígios - tanto individuais como coletivos - se dá pelo fato de que a prova ocupa, no processo de conhecimento, a essencialidade dos atos praticados, vez que sua finalidade é investigar o que realmente ocorreu diante do alegado pelas partes. Trata-se, portanto, de um elemento indispensável à entrega da tutela justa pelo Estado, sendo um instituto essencial para a melhor prestação do serviço público. ${ }^{36}$

Assim, os atos concertados entre juízes cooperantes (previstos no artigo 69, inciso IV, do Código de Processo Civil), quando interpretados conjuntamente à disposição do inciso II do mesmo artigo, permitem pensar, associando-os à ideia de gestão interna do Processo Civil, na agregação de causas que apresentem questões comuns de fato $^{37}$, o que possibilitaria uma produção una da prova necessária e, como consequência, economia de recursos financeiros, humanos e, também, de tempo. Trata-se, portanto, de conferir às questões de fato comuns um tratamento coletivo.

\section{Instrumentos de gestão probatória: o multidistrict litigation e a produção coletiva da prova.}

Partindo dessas premissas, buscou-se inspiração e influências no direito estrangeiro, que compreende, há muito, a relevância do tratamento coletivo em diversas questões atinentes ao processo. Deu-se especial atenção ao Direito Norte Americano, que no ano de $1842^{38}$ regulamentou, em caráter pioneiro, as suas ações coletivas - denominadas Class Actions -, regulamentação esta que é tida como modelo para a universalização do tratamento da tutela coletiva.

Nesse modelo encontramos um instituto denominado Multidistric Litigation que, como afirmado por Bruno Marzullo Zaroni, busca evitar o desperdício de tempo e recursos

\footnotetext{
${ }^{36}$ RODRIGUES, Marcelo Abelha. A distribuição do ônus da prova no Anteprojeto do Código Brasileiro de Processos Coletivos. In GRINOVER, Ada Pellegrini; MENDES, Aluisio Gonçalves de Castro; WATANABE, Kazuo (coord.) Direito Processual Coletivo e o Anteprojeto de Código Brasileiro de Processos Coletivos. São Paulo, Revista dos Tribunais, 2007, passim.

${ }^{37}$ LUNARDI, Thaís Amoroso Paschoal. Coletivização da Prova. Técnicas de produção coletiva da prova e seus reflexos na esfera individual (tese de doutorado). Curitiba: Universidade Federal do Paraná, 2018, passim. ${ }^{38}$ DONIZETTI, Elpídio; CERQUEIRA, Marcelo Malheiros. Curso de Processo Coletivo. $1^{\text {a }}$ ed. São Paulo, Atlas, 2010, p.1.
} 
financeiros, assim como a multiplicada prática dos mesmos atos processuais, sendo proveniente da ideia de que casos iguais devem ser tratados igualmente. ${ }^{39}$

Trata-se de técnica processual regulamentada em 1968 (28 U.S. Code $§ 1407$ ) que permite que as ações civis pendentes de julgamento em diversos tribunais federais americanos, que versem acerca de questões de fato comuns, sejam consolidadas temporariamente diante de um único juízo, a fim de possibilitar uma única fase instrutória, evitando gastos de recursos e tempo para produzir diversas vezes a mesma prova, que se adequa a todos os processos. ${ }^{40}$

É instrumento que permite, por exemplo, a aferição acerca da existência de nexo de causalidade entre ação/omissão de uma das partes e o dano suportado, de forma individual, por todos aqueles que pretendem mover ação indenizatória em face do suposto causador.

O procedimento se inicia no momento do pretrial, em que ocorre uma análise da situação fática e de direito de que trata cada ação, sendo que, para serem reunidas, devem apresentar uma ou mais semelhanças fáticas. Trata-se de momento extremamente relevante, que possibilita a resolução das causas comuns já no início do processo, seja por meio de acordos globais firmados entre as partes, seja por possibilitar ao litigante comum que oferte aos demais a adoção de modalidades alternativas/adequadas de resolução de conflitos.

Em suma, o que ocorre no MDL é a reunião das ações propostas perante diversos Juízos, diante de um único Juízo, o que pode se dar a partir de requerimento das partes ou, ainda, de ofício por parte do Judicial Painel of Multidistrict Litigation, órgão administrativo criado para conduzir a realização do Multidistrict Litigation, responsável pela eleição do Juízo em que se conduzirá a instrução probatória, denominado tranferee court, de forma a evitar a prática reiterada do mesmo ato processual. Concluída a fase instrutória, devolvemse as demandas para que sejam julgadas pelo juízo competente.

\footnotetext{
${ }^{39}$ ZARONI, Bruno Marzullo. Multidistrict Litigation: a Experiência Norte-Americana na Tutela dos Interesses de Massa. In Revista Magister de Direito Civil e Processual Civil, 2013, não paginado. Disponível em http://www.lex.com.br/doutrina_25632222_MULTIDISTRICT_LITIGATION_A_EXPERIENCIA_NORTE _AMERICANA_NA_TUTELA_DOS_INTERESSES_DE_MASSA.aspx. Acesso em 04 out. 2020.

40"Buscando promover a justa e eficiente solução das ações de conflitos coletivo de interesse, a fim de que ações que possuam fatos em comum, possam ser resolvidas de maneira mais eficiente e isonômica, a multidistrict litigation norte-americana trata de assuntos que interessem ao coletivo de pessoas, como acidentes de aviões, implantes de silicone, vacinas, práticas de vendas, antitrust e etc." RHODES, Blake M. Judicial Panel on Multidistrict Litigation: Time for Rethinking. University of. Pensilvania. Law. Review, v. 140, 1991, p. 711 .
} 
As críticas ao instrumento surgem quando o Judicial Painel elege o Juízo perante o qual as demandas serão reunidas, o que causa controvérsia entre as partes, uma vez que não existe um critério objetivo seguro para basilar essa decisão. São considerados, a princípio, a distribuição territorial das causas, o domicílio das partes envolvidas ou, ainda, das testemunhas a serem ouvidas, a experiência dos juízes do local e, também, o local de produção da prova necessária. ${ }^{41}$

Em um segundo momento, surgem questionamentos acerca da eleição do advogado, denominado lead counsel, que representará todos os litigantes diante do Juízo que conduzirá a fase instrutória. A escolha é realizada pelo Juízo eleito, que não possui critérios para fazêlo e, ainda, não tem o dever de justifica-la.

Ademais, levantam-se questões relativas à fase posterior à produção da prova, quando os autos são devolvidos ao Juízo originário para julgamento, eis que cada julgador analisará de forma singular a mesma prova, produzida no mesmo contexto, o que permite que ao mesmo caso sejam dadas soluções jurídicas diversas.

Por mais que apresente deficiências pontuais, o sistema é muito mais benéfico do que problemático. Estima-se, inclusive, que $40 \%$ das ações em trâmite perante as cortes federais estadunidenses, em algum momento, tenham se submetido ao MDL. ${ }^{42}$

Ademais, as demandas que tramitam no Multidistrict Litigation exigem do juiz uma atuação ativa que possibilita o conhecimento da causa de forma mais íntima que o julgador do caso individual, podendo antecipar eventuais problemas e decidir questões pontuais rapidamente, monitorando o desenvolvimento do processo periodicamente e, quando necessário, tendo o poder de readequar o seu plano de desenvolvimento. ${ }^{43}$

Desde sua criação, o Judicial Panel of Multidistrict Litigation analisou a centralização de mais de 250.000 casos envolvendo inúmeras matérias, como danos decorrentes de acidentes aéreos, de trem ou incêndios em hotéis; danos decorrentes de amianto ou medicamentos, ou próteses de silicone. As ações propostas em razão dos danos

\footnotetext{
${ }^{41}$ KLONOFF. Robert H. Class Actions and Other MultiParty Litigation in a Nutshell. West Group, St. Paul, Minn., 1999, p. 336-337

${ }^{42}$ BRADT, Andrew. The long arm of multidistrict litigation. Williamsburg: William e Mary Law Review, 2018, p. 1168.

${ }^{43}$ ZARONI, Bruno Marzullo. Multidistrict Litigation: a Experiência Norte-Americana na Tutela dos Interesses de Massa. In Revista Magister de Direito Civil e Processual Civil, 2013, não paginado. Disponível em http://www.lex.com.br/doutrina_25632222_MULTIDISTRICT_LITIGATION_A_EXPERIENCIA_NORTE _AMERICANA_NA_TUTELA_DOS_INTERESSES_DE_MASSA.aspx. Acesso em 04 out. 2020.
} 
(ataques cardíacos e acidentes vasculares) gerados pelo uso do medicamento Vioxx, por exemplo, resultaram em um MDL no qual foi realizado um acordo de mais de 4,85 bilhões de dólares. ${ }^{44}$

Além disso, a reunião das causas aumenta consideravelmente a composição de acordos globais, sendo que o juiz que possui maior familiaridade com a causa possui mais chance de promover a transação entre as partes. Inclusive, constatou-se que apenas em 3\% das causas submetidas ao procedimento não houve composição da controvérsia perante a transferee court. ${ }^{45}$

Um caso emblemático submetido ao Multidistrict Litigation, capaz de ilustrar as suas inúmeras vantagens, é o reconhecido como Silicone Gel Breast Implants, que foi consolidado pelo Panel no ano de 1992. Essa decisão decorreu da existência de 78 ações individuais que se encontravam pendentes de julgamento, diante de 33 distritos do sistema federal americano. Todas as ações tinham como objeto o dano causado por implantes de silicone em gel e a apuração da responsabilidade dos fabricantes quanto aos citados danos.

Posteriormente à consolidação do procedimento, surgiram mais de 10 mil tag-along $\operatorname{cases}^{46}$, que seguiram para o tribunal cessionário, qual seja, o Distrito da Califórnia, onde ocorreram os procedimentos de instrução e saneamento do processo, que acabou sendo extinto por meio da celebração de um acordo no valor de um bilhão de dólares.

Sem a adoção do procedimento do Multidistrict Litigation, haveria a necessidade de que múltiplas ações tramitassem perante o Poder Judiciário, sendo que, em cada uma delas, se desenvolveria uma fase de saneamento e uma instrução probatória autônomas, em que haveria a necessidade de tomada de depoimentos de partes e testemunhas replicadas vezes.

No caso supracitado, a tomada de depoimento do representante da fabricante do produto foi realizada apenas uma vez. Sem que houvesse o agrupamento das causas por meio do Multidistrict Litigation, a tomada do mesmo depoimento seria realizada, no mínimo, 78

\footnotetext{
${ }^{44}$ Ibidem, não paginado.

45 BRADT, Andrew. The long arm of multidistrict litigation. Williamsburg: William e Mary Law Review, 2018, p. 1169.

${ }^{46}$ Tag-along cases são ações pendentes em tribunais distritais que envolvem questões de fato com moções pendentes para transferir e criar uma demanda sob a ótica do Multidistrict Litigation ou, então, transferir a causa para um MDL já existente.
} 
vezes. Evidente, portanto, a economia dos recursos materiais do Poder Judiciário proporcionada pelo instituto.

Ainda, o Multidistrict Litigation possibilita que se forneça um tratamento isonômico aos processos, de forma mais simplificada. Sendo a mesma prova produzida para as causas caracterizadas por questões comuns de fato, menor é a probabilidade de que se alcancem conclusões distintas. Com a consolidação de um MDL, as questões controvertidas, as provas produzidas, os testemunhos e documentos solicitados, são replicados a todas as ações de forma mais eficiente, garantindo maior isonomia para os casos julgados.

Outra vantagem da instituição do Multidistrict Litigation, é a amplificação do acesso à Justiça. É costumeiro que as ações sobre as quais ele versa sejam ajuizadas em face de grandes fabricantes e, em virtude do alto custo do acesso ao Poder Judiciário nos Estados Unidos, é comum que os demandantes que não se encontrem em paridade de condições com grandes fabricantes deixem de ajuizar a ação por meio da qual se buscaria a tutela do seu direito. No caso apresentado, muitos demandantes teriam o acesso à Justiça restrito em virtude dos altos custos dos processos, o que restou demonstrado pelo grande número de tagalong cases transferidos após a consolidação do MDL.

Desde sua instituição em 1968, surgido da necessidade de um procedimento de resolução de litígios em massa dentro dos tribunais federais americanos, o Multidistrict Litigation apresentou vantagens e, para sua finalidade institucional, vem mostrando efetividade ao longo desses 50 anos.

Segundo Burch, até 2015, os procedimentos de MDL representavam 39\% do total de casos civis dos tribunais federais americanos, sendo que, da sua instituição, no ano de 1968, até o ano fiscal de 2017, $80 \%$ das ações sujeitas ao procedimento foram solucionadas. $^{47}$

\section{Conclusão}

O Multidistrict Litigation é um instituto processual que possibilita a agregação de causas que versem sobre questões comuns de fato, oportunizando uma fase de instrução

\footnotetext{
${ }^{47}$ BURCH, Elizabeth Chamblee. Monopolies in Multidistrict Litigation. 70 Vand. L. Rev. 67, 2017, p.72. Disponível em http://digitalcommons.law.uga.edu/fac_artchop/1113. Acesso em 06 mai. 2018.
} 
probatória una, o que acompanha uma série de benefícios como a economia de recursos, o estímulo à celebração de acordos globais e uma maior garantia de segurança jurídica, sendo uma forma adequada de tratar as causas que atingem uma coletividade de demandantes.

Devidamente adaptado ao sistema brasileiro, o Multidistrict Litigation independe de uma proposta de lege ferenda, sendo instituto que poderia, com facilidade, por meio dos atos concertados entre juízes cooperantes (arts. 69, §2, CPC), prestar um adequado tratamento às questões de massa.

\section{REFERÊNCIAS}

ARENHART, Sérgio Cruz. A Tutela Coletiva de Interesses Individuais: para além da proteção dos interesses individuais homogêneos. $1^{\mathrm{a}}$ ed. em e-book baseada na $2^{\mathrm{a}}$ ed. impressa. São Paulo: Revista dos Tribunais, 2015, não paginado.

ARENHART, Sérgio Cruz. OSNA, Gustavo. Curso de Processo Civil Coletivo. $2^{\mathrm{a}}$ ed. São Paulo: Revista dos Tribunais, 2020.

ARENHART, Sérgio Cruz. Perfis da tutela inibitória coletiva. São Paulo: Revista dos Tribunais, 2003.

BEDAQUE, José Roberto dos Santos. Efetividade do processo e técnica processual. São Paulo: Malheiros, 2006.

BRADT, Andrew. The long arm of multidistrict litigation. Williamsburg: William e Mary Law Review, 2018.

BRASIL. Código de Processo Civil e normas correlatas, 7. ed. Exposição de motivos. Brasília: Senado Federal, Coordenação de Edições Técnicas, 2015. Disponível em https://www2.senado.leg.br/bdsf/bitstream/handle/id/512422/001041135.pdf, acesso em 15 set 2020.

BRASIL. Conselho Nacional de Justiça. Estudo comparado sobre recursos, litigiosidade e produtividade: a prestação jurisdicional no contexto internacional. Disponível em https://www.cnj.jus.br/wp-content/uploads/2011/02/relat_estudo_comp_inter.pdf Acesso em 11. Set. 2020.

BRASIL. Conselho Nacional de Justiça. Justiça em números 2019: ano-base 2018. Brasília: CNJ, 2019. 
BRASIL. Conselho Nacional de Justiça. Justiça em números 2020: ano-base 2019. Brasília: CNJ, 2020.

BRASIL. Conselho Nacional de Justiça. 100 Maiores Litigantes. Brasília, 2011, p. 5. Disponível em https://www.cnj.jus.br/wpcontent/uploads/2011/02/pesquisa_100_maiores_litigantes.pdf. Acesso em 08 set. 2020 .

BURCH, Elizabeth Chamblee. Monopolies in Multidistrict Litigation. 70 Vand. L. Rev. 67, 2017. Disponível em http://digitalcommons.law.uga.edu/fac_artchop/1113. Acesso em 06 mai. 2018.

CAPONI, Remo. O princípio da proporcionalidade na Justiça Civil. In Revista de Processo n. 192. São Paulo: Revista dos Tribunais, 2011.

CASTRO, Alexandre Samy. Indicadores Básicos e Desempenho da Justiça Estadual de $\begin{array}{lllll}\text { Primeiro } & \text { Grau no } & \text { Brasil. }\end{array}$ http://www.ipea.gov.br/portal/index.php?option=com_content\&view=article\&id=96 05. Acesso em 12 ago. 2020

DONIZETTI, Elpídio; CERQUEIRA, Marcelo Malheiros. Curso de Processo Coletivo. $1^{\text {a }}$ ed. São Paulo, Atlas, 2010.

GRINOVER, Ada Pellegrini. Deformalização do processo e deformalização das controvérsias. In Revista de Processo n. 46. São Paulo: Revista dos Tribunais, 1987.

GRINOVER, Ada Pellegrini; WATANABE, Kazuo; MULLENIX, Linda. Os processos coletivos nos países de civil law e common law: uma análise de direito comparado. $1^{\text {a }}$ ed. São Paulo, Revista dos Tribunais, 2008.

JUNIOR, Fredie Didier; ZANETTI, Hérmes. Curso de Direito Processual Civil: Processo Coletivo. V.4, 14 ed. Salvador: JusPodivm: 2020.

KLONOFF. Robert H. Class Actions and Other MultiParty Litigation in a Nutshell. West Group, St. Paul, Minn., 1999.

LUNARDI, Thais Amoroso Paschoal. Atos concertados entre juízes cooperantes como ferramenta adequada de gestão processual: uma possibilidade para a aplicação do multidistrict litigation no sistema brasileiro. In ARENHART, Sérgio Cruz; MITIDIERO, Daniel (coord.). Processo Civil entre a Técnica Processual e a Tutela 
Dos Direitos: Estudos Em Homenagem A Luiz Guilherme Marinoni. São Paulo: Revista dos Tribunais, 2017.

LUNARDI, Thaís Amoroso Paschoal. Coletivização da Prova. Técnicas de produção coletiva da prova e seus reflexos na esfera individual (tese de doutorado). Curitiba: Universidade Federal do Paraná, 2018.

MANCUSO, Rodolfo de Camargo. Interesses Difusos: conceito e legitimação para agir. $6^{\mathrm{a}}$ ed. São Paulo, Revista dos Tribunais, 2004.

MARINONI, Luiz Guilherme. Teoria geral do processo. São Paulo: Revista dos Tribunais, 2006.

MILARÉ, Edis; CASTANHO, Renata. A distribuição do ônus da prova no Anteprojeto de Código Brasileiro de Processos Coletivos. In GRINOVER, Ada Pellegrini; MENDES, Aluisio Gonçalves de Castro; WATANABE, Kazuo (coord.) Direito Processual Coletivo e o Anteprojeto de Código Brasileiro de Processos Coletivos. São Paulo, Revista dos Tribunais, 2007.

MITIDIERO, Daniel. Bases para a construção de um Processo Civil Cooperativo: o direito processual civil no marco teórico do formalismo-valorativo (tese de doutorado). Porto Alegre: Universidade Federal do Rio Grande do Sul, 2007.

OSNA, Gustavo. Direitos Individuais Homogêneos: Pressupostos, fundamentos e aplicação no processo civil. $1^{\text {a }}$ ed. São Paulo: Revista dos Tribunais, 2014.

RHODES, Blake M. Judicial Panel on Multidistrict Litigation: Time for Rethinking. University of. Pensilvania. Law. Review, v. 140, 1991.

RODRIGUES, Marcelo Abelha. A distribuição do ônus da prova no Anteprojeto do Código Brasileiro de Processos Coletivos. In GRINOVER, Ada Pellegrini; MENDES, Aluisio Gonçalves de Castro; WATANABE, Kazuo (coord.) Direito Processual Coletivo e o Anteprojeto de Código Brasileiro de Processos Coletivos. São Paulo, Revista dos Tribunais, 2007.

TARUFFO, Michele. La prueba. $1^{\text {a }}$ ed. Madrid: Marcial Pons, 2008.

TARUFFO, Michele. Some Remarks on Group Litigantion in Comparative Perspective. In Duke Journal of Comparative \& International Law, n. 11. Durham: Duke Universtity, 2001. Disponível em https://scholarship.law.duke.edu/djcil/vol11/iss2/12 acesso em 13 set. 2020. 
VITORELLI, Edilson. Processo Civil Estrutural. Salvador: JusPodivm, 2020.

ZARONI, Bruno Marzullo. Multidistrict Litigation: a Experiência Norte-Americana na Tutela dos Interesses de Massa. In Revista Magister de Direito Civil e Processual Civil, 2013, não $\quad$ paginado. Disponível em http://www.lex.com.br/doutrina_25632222_MULTIDISTRICT_LITIGATION_A_E XPERIENCIA_NORTE_AMERICANA_NA_TUTELA_DOS_INTERESSES_DE_ MASSA.aspx . Acesso em 04 out. 2020. 